\title{
The Effect of the Artificial Aging on the Precipitation Kinetic in the Al-Mg-Si Alloy
}

\author{
I. Hamdi ${ }^{1}$ and Z. Boumerzoug ${ }^{2}$ \\ 1. Department of Chemical Industry, University of Biskra, Biskra, Algeria \\ 2. Department of Mechanical Engineering, University of Biskra, Biskra, Algeria
}

\begin{abstract}
In this study, the effect of the artificial aging on the kinetics of the precipitation processes in the Al-Mg-Si alloy was investigated by differential scanning calorimetry and hardness examinations. This investigation revealed that the artificial aging has a positive effect on the precipitation kinetic. The activation energy of the precipitation process was calculated using Kissinger model. The result of this study showed a change in hardness values and in the activation energy for all precipitated phases. The hardness has high values at the higher aging temperature. The activation energy of the metastable phase $\beta^{\prime \prime}$ is determined as 41.55 , which indicates that the formation of this phase is uncomplicated during artificial aging.
\end{abstract}

Key words: $\mathrm{Al}-\mathrm{Mg}-\mathrm{Si}$, precipitation, $\beta^{\prime \prime}$, kinetic, DSC.

\section{Introduction}

The 6000 series Al-Mg-Si alloys are the commercially most frequently used Al-based alloys since they can be age-hardened to medium strength while also having many other favorable properties [1]: excellent corrosion resistance; favorable formability and low density; and are widely used in both cast and wrought forms. The precipitation hardening is a process that involves a particulate dispersion of obstacles to dislocation movements in alloys resulting in strengthening the alloy component. The precipitation sequence during aging at constant temperature of quenched $\mathrm{Al}-\mathrm{Mg}-\mathrm{Si}$ alloys can be expressed as: SSSS (Supersaturated solid solution) $\rightarrow$ atomic clusters $\rightarrow$ G.P. zones $\rightarrow \beta^{\prime \prime} \rightarrow \beta^{\prime} \rightarrow \beta$ (stable) $[2,3]$.

The $\beta^{\prime \prime}$ precipitates are fine needle shaped zones with monoclinic structure [4], it is the main strengthening phase in Al-Mg-Si alloys [5].

In recent years, many researchers [6] focused on the kinetics parameters in $\mathrm{Al}-\mathrm{Mg}$-Si during artificial aging due to the great importance of understanding the phase

Corresponding author: I. Hamdi, Dr., research field: phase transformation. transformation mechanisms.

The aim of this study is to clarify the effect of the artificial aging on the kinetics of the precipitation processes in the Al-Mg-Si alloy by means of hardness measurement and DSC as analysis technique.

\section{Experimental}

The composition of the materials used is shown in Table 1. DSC tests were carried out using a Q 20 TA analyzer. The samples for the DSC measurements were cut from rods with $3 \mathrm{~mm}$ diameter and 2-2.5 $\mathrm{mm}$ height. The resulting weight is between 30 and $50 \mathrm{mg}$. They were homogenized at $550{ }^{\circ} \mathrm{C}$ for $6 \mathrm{~h}$ and quenched in water. Each sample was processed with three different heating rates $\left(25,30\right.$ and $\left.40{ }^{\circ} \mathrm{C} / \mathrm{min}\right)$ from room temperature to $550{ }^{\circ} \mathrm{C}$ in $\mathrm{N}_{2}$ atmosphere.

Micro-Vickers hardness measurements are taken by Digital Micro-Vickers Hardness Tester type HVS-1000 Z under load of $200 \mathrm{~g}$. Each hardness value is the average value from five individual tests. The specimens for the Vickers hardness measurements were also homogenized at $550{ }^{\circ} \mathrm{C}$ for $6 \mathrm{~h}$ and quenched in water before artificial aging treatment at 150,175 and $200{ }^{\circ} \mathrm{C}$ for different times. 
Table 1 Chemical composition of investigated Al-Mg-Si alloy.

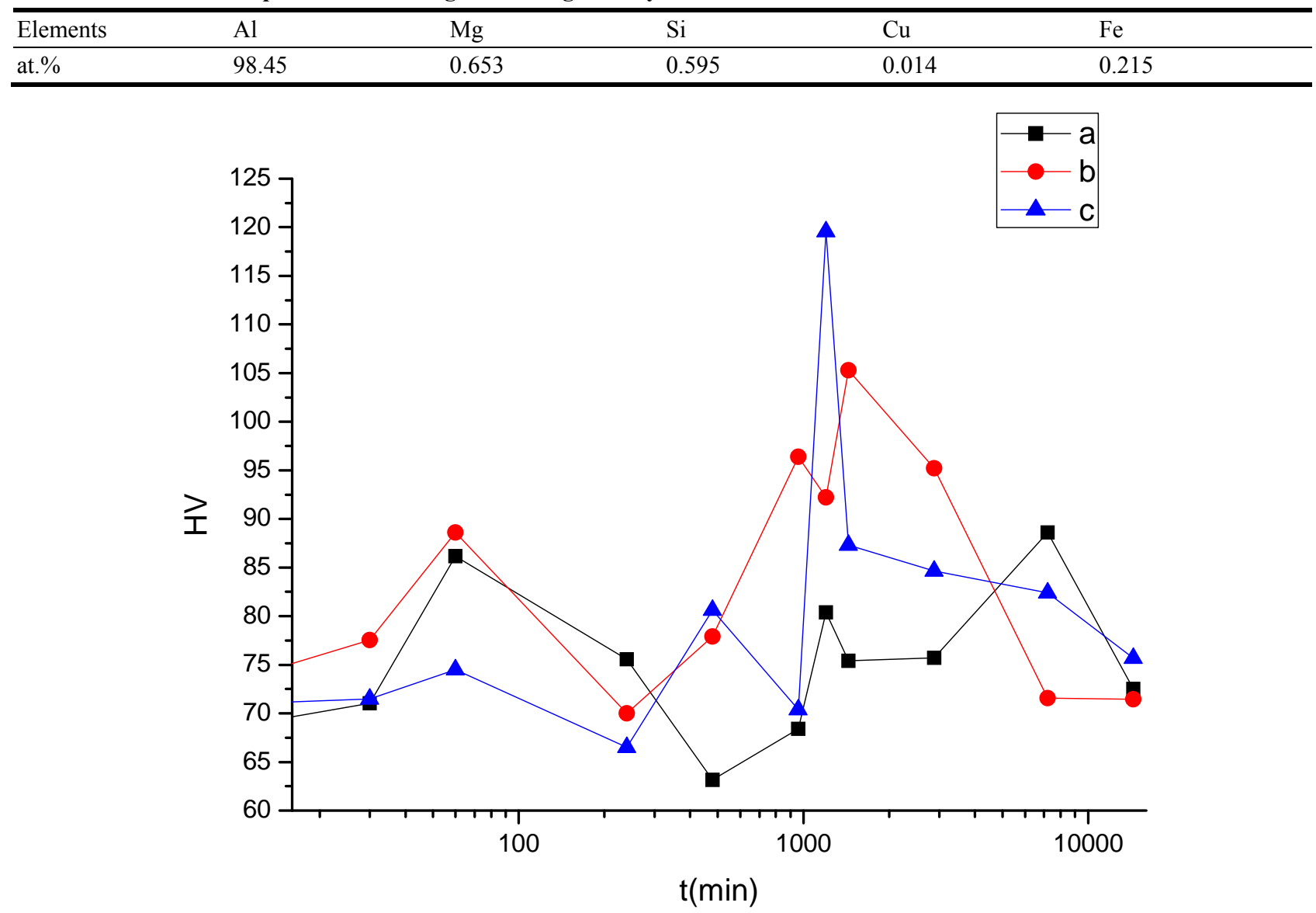

Fig. 1 Hardness variation versus aging time of a quenched Al-Mg-Si alloy aging at a) $\left.150{ }^{\circ} \mathrm{C}, \mathrm{b}\right) 175^{\circ} \mathrm{C}$ and c) $200{ }^{\circ} \mathrm{C}$.

\section{Results and discussion}

\subsection{Hardness Measurement}

Fig. 1 shows the Vickers hardness measurements of a quenched Al-Mg-Si alloy aging at 150,175 and $200^{\circ} \mathrm{C}$. All the curves exhibited the similar hardening sequence. The initial stage corresponds to the formation of the GP zones and the maximum hardening is corresponding to the formation of $\beta^{\prime \prime}$ phase. The hardness values during artificial aging at $200{ }^{\circ} \mathrm{C}$ are higher than that in artificial aging at 150 and $175{ }^{\circ} \mathrm{C}$. But the time of the phase's formation decrease.

After quenching of the sample, the clusters start to form and grow which slow down the vacancies and consequently rate of clustering will decrease. Higher aging temperature increases the different of vacancies and solute atoms. This should result in a faster kinetics of clustering. So the increase of the temperature accelerates the formation of the precipitate which has a positive effect on the precipitation kinetics $[7,8]$.

\subsection{DSC Tests}

Fig. 2 shows the DSC thermo-grams of the quenched alloy during different heating rate $(25,30$ and $40{ }^{\circ} \mathrm{C} / \mathrm{min}$ ). DSC curves show four exothermic peaks which correspond to the formation of GP zones (peak A), $\beta^{\prime \prime}$ (peak C), $\beta^{\prime}$ (peak E) and $\beta$ (peak G), and four endothermic peaks $(B, D, F$ and $H)$ which correspond to the dissolution of GP zones, the metastable phase $\beta^{\prime \prime}, \beta^{\prime}$ and the stable phase $\beta$ respectively. The main precipitation peaks increase and shift to higher temperatures with the decrease of 


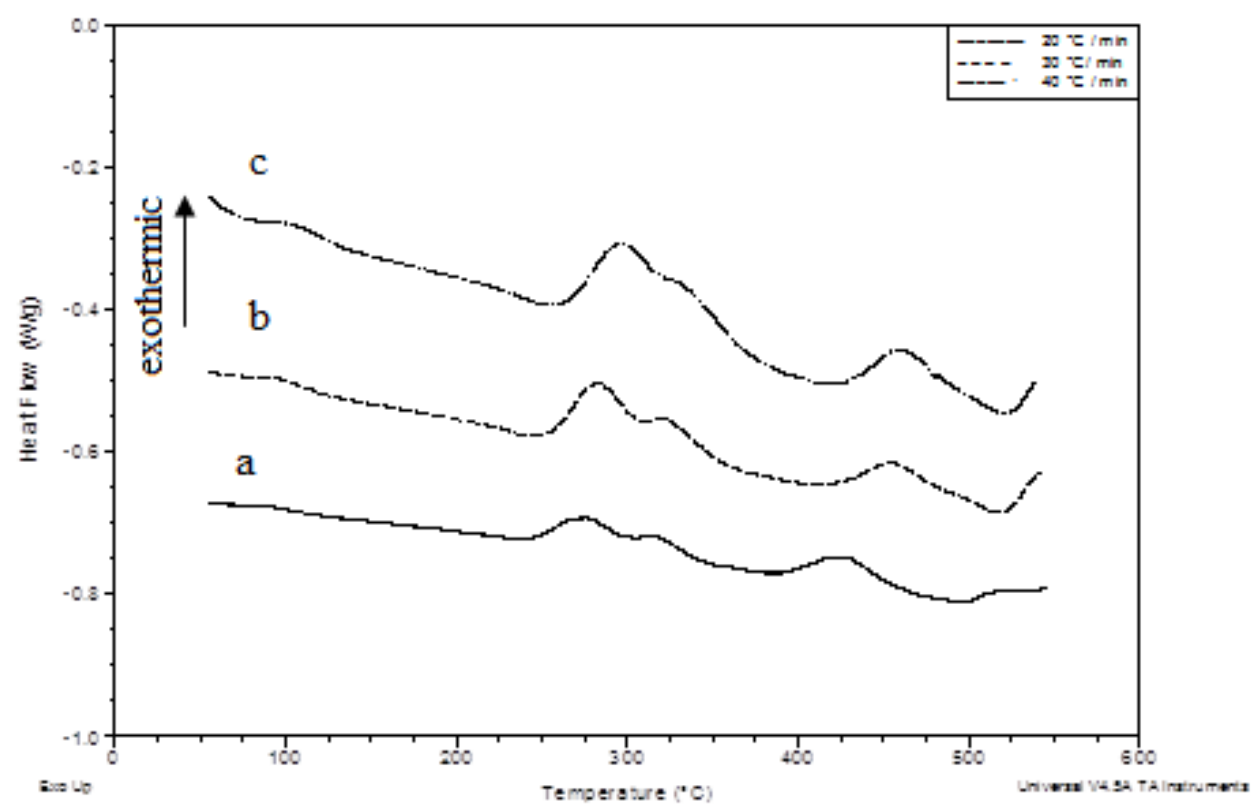

Fig. 2 DSC curves of quenched Al Mg Si alloy at different heating rates: (a) $\alpha=25^{\circ} \mathrm{C} / \mathrm{min}$, (b) $\alpha=30{ }^{\circ} \mathrm{C} / \mathrm{min}$ and (c) $\alpha=$ $40{ }^{\circ} \mathrm{C} / \mathbf{m i n}$.

Table 2 Variation of DSC peak temperature with heating rate $\alpha\left({ }^{\circ} \mathrm{C} / \mathrm{min}\right)$.

\begin{tabular}{lllll}
\hline Phase & GP & $\beta^{\prime \prime}$ & $\beta^{\prime}$ & $\beta$ \\
\hline $\mathrm{V}$ & $90.28^{\circ} \mathrm{C}$ & $261.43^{\circ} \mathrm{C}$ & $315.65^{\circ} \mathrm{C}$ & $424.88^{\circ} \mathrm{C}$ \\
$25^{\circ} \mathrm{C} / \min$ & $95.07^{\circ} \mathrm{C}$ & $281.55^{\circ} \mathrm{C}$ & $323.64{ }^{\circ} \mathrm{C}$ & $454.71{ }^{\circ} \mathrm{C}$ \\
$30^{\circ} \mathrm{C} / \min$ & $100.93^{\circ} \mathrm{C}$ & $295.94^{\circ} \mathrm{C}$ & $328.97{ }^{\circ} \mathrm{C}$ & $460.04{ }^{\circ} \mathrm{C}$ \\
$40^{\circ} \mathrm{C} / \min$ & &
\end{tabular}

heating rate, which means that this transformation is thermally activated.

The activation energy for precipitation, $\mathrm{E}$, is determined by Kissinger [9] method of the four exothermic peaks detected in Fig. 1. This method was basically developed in order to study the variation of the maximum peak temperature with heating rate, (Table 2), according to the following expression:

$$
\ln \left(\frac{\alpha}{T_{p}^{2}}\right)=-\frac{E}{R T_{p}^{2}}+\text { constant }
$$

Where $\alpha$ is the heating rate, Tp is the temperature of the peak maximum, and $\mathrm{R}$ is the gas constant $(8.314 \mathrm{~J}$ $\mathrm{mol}^{-1} \mathrm{~K}^{-1}$ ).

Fig. 3 illustrates the linear relationships between $\ln$ $\left(\alpha / \mathrm{Tp}^{2}\right)$ and $1000 / \mathrm{Tp}$. The activation energy $E$ is determined from each slope (Table 3 ).
The activation energy associated with the formation of the GP zones is found $66.894 \mathrm{~kJ} / \mathrm{mol}$. This value is found close to that for the migration vacancies.

The activation energy associated with the precipitation of the $\beta^{\prime \prime}$ phase is found $143.059 \mathrm{~kJ} / \mathrm{mol}$. This value is found close to the diffusion energies of $\mathrm{Mg}, \mathrm{Si}$ and $\mathrm{Al}$ which have the following values (131 $\left.\mathrm{kJ} \mathrm{mol}^{-1}\right)$ [10] and (124 $\left.\mathrm{kJ} \mathrm{mol}^{-1}\right)$ [11] respectively. Therefore, this precipitation process can be controlled by the diffusion of $\mathrm{Mg}$, and $\mathrm{Si}$ in the $\mathrm{Al}$ matrix.

The activation energies obtained for the GP zones, $\beta^{\prime \prime}$ and the $\beta$ formation in the Al-Mg-Si alloy during artificial aging are higher than the value of the $\beta^{\prime \prime}$ formation. It indicates that the artificial aging have influence on the formation of the metastable phase $\beta^{\prime \prime}$. 


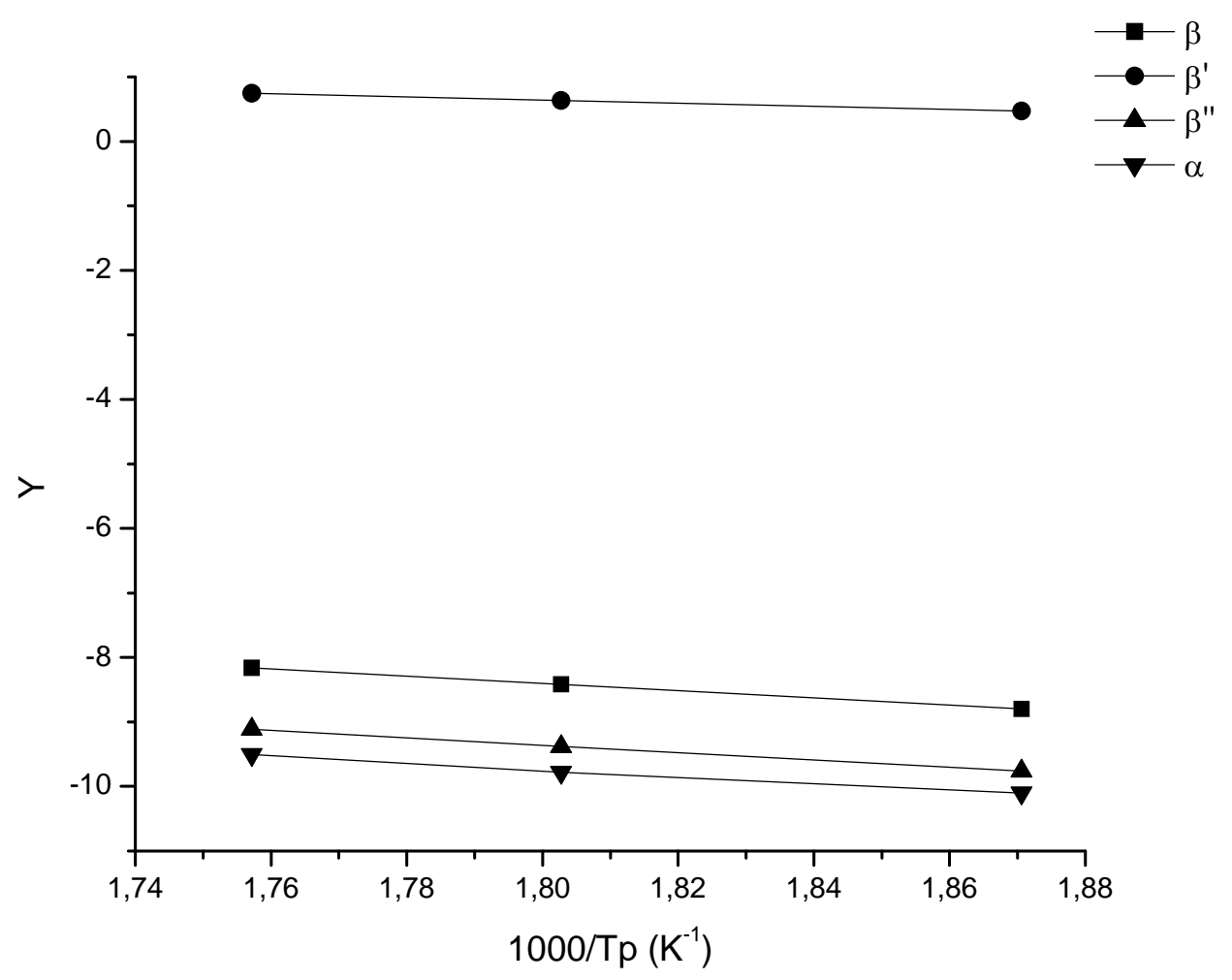

Fig. 3 The linear relationships between $\ln \left(\alpha / \mathrm{Tp}^{2}\right)$ and 1,000/Tp $\left(\alpha, \beta^{\prime \prime}, \beta^{\prime}\right.$ and $\left.\beta\right)$.

Table 3 The value of activation energy $E(\mathrm{~kJ} / \mathrm{mol})$.

\begin{tabular}{lllll}
\hline Phase & GP & $\beta^{\prime \prime}$ & $\beta^{\prime}$ & $\beta$ \\
\hline Activation energy (kJ/mol) & 66.894 & 41.555 & 143.059 & 62.845 \\
\hline
\end{tabular}

\section{Conclusion}

In this work, the effect of the artificial aging on the kinetics of the precipitation processes in the Al-Mg-Si alloy has been studied by using differential scanning calorimetry and hardness examinations. The following conclusions can be drawn:

- The hardness values of the precipitation phases decrease with the decrease of the temperature.

- The artificial aging improves the strength of the Al Mg Si alloy.

- The artificial aging has a positive effect on the precipitation kinetics.

- The activation energy for the GP zones, $\beta^{\prime \prime}, \beta^{\prime}$ and the $\beta$ is determinated as $66.894,41.555,143.059$ and $62.845 \mathrm{~kJ} / \mathrm{mol}$ respectively.

- During artificial aging, the persistent phase $\beta^{\prime \prime}$ was formed.

\section{References}

[1] Banhart, J., Ting Chang, C. S., Liang, Z., Wanderka, N., Lay, M. D. H., and Hill, A. J. 2010. "Natural Ageing in Al-Mg-Si Alloys-a Process of Unexpected Complexity." Advanced Engineering Materials 12 (7): 559-71.

[2] Thomas, G. J. 1961-62. "The Aging Characterization of Aluminum Alloys Electro Transmission Studies of Al-Mg-Si Alloys." Institute of Metals 90: 57-63.

[3] Matsuda, K., Ishida, Y., Müllerová, I., Frank, L., and Ikeno, S. 2006. "Cube-Phase in Excess Mg Type AlMg-Si Alloy Studied by EFTEM.” Materials Science 41: 2605-10.

[4] Liua, M., Wua, Z., Yanga, R., Weia, J., Yub, Y., Skaretb, P., and Rovenb Hans, J. 2015. "DSC Analyses of Static and Dynamic Precipitation of an $\mathrm{Al}-\mathrm{Mg}-\mathrm{Si}-\mathrm{Cu}$ Aluminum Alloy." Progress in Natural Science: Materials International 25: 153-8.

[5] Hossein, S. 2007. "Early Stages of Ageing in Al-Mg-Si Alloys." Mc master university, 95.

[6] Wenner, S. 2014. "Transmission Microscopy and Muon Spin PHD." Norwegian university of science and 
technology.

[7] Panseri, C., Federighi, T., and Cersare, S. 1963. "Recovery of Aluminum Cold Worked by Compression at $78 \mathrm{~K}$." Transmis of Metallurgical Society of AIME 227: 1122-6.

[8] Ozawa, E., and Kimura, H. 1970. "Excess Vacancies and the Nucleation of Precipitates in Aluminum-silicon Alloys." Acta Metallurgica 18: 995-1004.

[9] Kissinger, H. E. 1957. "Reaction Kinetics in Differential
Thermal Analysis.” Analytical Chemistry 29: 1702.

[10] Abo Zeid, E. F., and Kim, Y. T. 2010. "Investigation of Developed Precipitates in $\mathrm{Al} \mathrm{Mg} \mathrm{Si} \mathrm{Alloys} \mathrm{with} \mathrm{and}$ without Excess Si." Materials Science and Technology 26: 440-4.

[11] Gaber, A., Yassar, R. S., Field, D. P., and Weiland, H. 2005. "The Effect of Cold Deformation on the Kinetics of the $\beta$ " Precipitates in an Al-Mg-Si Alloy." Metallurgical and Materials Transactions 36: 2059-265. 